Article

\title{
Digitalization as a Strategic Means of Achieving Sustainable Efficiencies in Construction Management: A Critical Review
}

\author{
Bahareh Nikmehr ${ }^{1}$ (D, M. Reza Hosseini ${ }^{1}{ }^{1} * \mathbb{C}$, Igor Martek ${ }^{1}$, Edmundas Kazimieras Zavadskas ${ }^{2}$ (I) \\ and Jurgita Antucheviciene ${ }^{3}$ \\ 1 School of Architecture and Built Environment, Deakin University, Geelong, VIC 3220, Australia; \\ bnikmehr@yahoo.com (B.N.); igor.martek@deakin.edu.au (I.M.) \\ 2 Institute of Sustainable Construction, Vilnius Gediminas Technical University, LT-10223 Vilnius, Lithuania; \\ edmundas.zavadskas@vilniustech.lt \\ 3 Department of Construction Management and Real Estate, Vilnius Gediminas Technical University, \\ LT-10223 Vilnius, Lithuania; jurgita.antucheviciene@vilniustech.lt \\ * Correspondence: reza.hosseini@deakin.edu.au
}

Citation: Nikmehr, B.; Hosseini, M.R.; Martek, I.; Zavadskas, E.K.; Antucheviciene, J. Digitalization as a Strategic Means of Achieving Sustainable Efficiencies in Construction Management: A Critical Review. Sustainability 2021, 13, 5040 https://doi.org/10.3390/su13095040

Academic Editor: Sunkuk Kim

Received: 23 March 2021

Accepted: 27 April 2021

Published: 30 April 2021

Publisher's Note: MDPI stays neutral with regard to jurisdictional claims in published maps and institutional affiliations.

Copyright: (c) 2021 by the authors. Licensee MDPI, Basel, Switzerland. This article is an open access article distributed under the terms and conditions of the Creative Commons Attribution (CC BY) license (https:// creativecommons.org/licenses/by/ $4.0 /)$.

\begin{abstract}
Construction is a complex activity, characterized by high levels of capital investment, relatively long delivery durations, multitudinous risks and uncertainties, as well as requiring the integration of multiple skills delivering a huge volume of tasks and processes. All of these must be coordinated carefully if time, cost, and quality constraints are to be met. At the same time, construction is renowned for performing poorly regarding sustainability metrics. Construction activity generates high volumes of waste, requires vast amounts of resources and materials, while consuming a significant proportion of total energy generated. Digitalization of the construction workplace and construction activities has the potential of improving construction performance both in terms of business results as well as sustainability outcomes. This is because, to put it simply, reduced energy usage, for example, impacts economic and "green" performance, simultaneously. Firms tinkering with digitalization, however, do not always achieve the hoped-for outcomes. The challenge faced is that a digital transition of construction firms must be carried out at a strategic level—requiring a comprehensive change management protocol. What then does a digital strategy entail? This study puts forward an argument for the combined economic and sustainability dividends to be had from digitizing construction firm activities. It outlines the requirements for achieving digitalization. The elements of a comprehensive digitalization strategy are cataloged, while the various approaches to developing a digitalization strategy are discussed. This study offers practitioners a useful framework by which to consider their own firm-level efforts at digitalization transition.
\end{abstract}

Keywords: digital transformation; digital technology; sustainability; strategy; construction management; change management

\section{Introduction}

The construction industry is one of the largest sectors of the global economy [1]. On a global scale, construction-related spending accounts for $13 \%$, and the total annual revenue of the sector is estimated to be around $\$ 10$ trillion, predicted to be up to $\$ 14$ trillion by 2025 [1]. The construction industry has also one of the greatest economic spillover effects, namely, it represents an additional economic benefit of $\$ 2.86$ for every $\$ 1$ of construction Gross Domestic Product (GDP) [2]. As a result, even a slight improvement in the sector will carry huge positive implications for the national economy $[2,3]$.

Despite its significance, the construction industry is still struggling with a wide range of problems: high construction costs; unsatisfactory project performance [4]; poor site safety records; low construction productivity; a lack of creativity and innovation; and above all poor sustainability outcomes [3,5-7]. Several developments offer the potential of mitigating these pitfalls, of which, the most promising is industry reform through digitalization $[5,8,9]$. 
Digitalization benefits any industry in various ways: greater convenience, lower prices, variety of choice, better information, enhanced sustainability, and the profitability of existing business models and investments $[10,11]$. Better business models, cost reduction, improved quality of communications, enhanced customer satisfaction, and so forth are other advantages of digital technologies. Indeed, these are interrelated where improvements across any economic, social and environmental outcomes collectively contribute to a more sustainable construction industry [12-15]. Given these potentials, digitalization has emerged as instrumental in driving sector change [16]. Traditional resistance to efforts at making construction more sustainable has been that it costs too much. However, the evidence shows that the potential added value of digitalization could be around $\$ 25$ billion annually in the years 2017-2027, in Australia alone, while at the same time improving sustainability outcomes [8].

Digitalization can be simply defined as the use of digital technologies to change business models to increase revenue and value-producing opportunities for companies and businesses; the term refers to the process of moving to a digital business [17,18]. Digitalization is largely seen as a powerful intervention into the core business of companies and is associated with organization-wide modernization efforts affecting all structures, systems, and processes within companies $[18,19]$. Similarly, sustainability is widely defined as meeting the needs of the present without compromising the ability of future generations to meet their future needs. In practical terms, this breaks down into three mutually inclusive "bottom-line" measures. Present economic outcomes must be improved in ways that do not undermine future economic growth; present use of resources must be undertaken in ways that do not degrade the environment of the future; and social justice must be pursued such that nobody is left excluded, disadvantaged, or otherwise denied from an equitable share of accrued societal gains.

This paper argues that in order to successfully absorb the economic and sustainability benefits of digitalization into construction companies, appropriate digitalization adoption strategies must be proactively adopted. Thus, the factors and steps required in order to implant a successful digitalization strategy are here outlined. To this end, this paper begins by identifying the driving forces compelling the digitalization of construction firms. Next, the role of digitalization strategies along with the various approaches to digitalization available to construction companies are discussed. The paper concludes by describing the required steps for the development of a construction company-specific digitalization strategy able to meet economic and sustainability performance improvement outcomes simultaneously.

\section{The Digital Transformation of the Construction Industry}

Innovations comprise a wide range of transformative systems, from lean concepts through to information and communications technologies [20]. These innovations are enablers that reduce industrial process emissions and energy consumption from manufacturing construction components, to construction, operations, and building decommissioning. Their underlying intelligent operating platforms and automated solutions have the potential to optimize task outcomes, and in so doing greatly limit the otherwise adverse effects of traditional systems and processes regarding greenhouse gas emissions, pollution, and indeed even on potentially exploitative or hazardous work practices [21].

Construction companies seek remedial solutions to these issues [22], as a result of which, the field observes an increasing shift towards the use of digital technologies in the construction industry [23]. Evidence shows that they can benefit from various technological innovations in delivering projects [23]. Technological innovations can overcome a wide range of challenges that affect the construction industry, including cost overruns, rework, low project performance, poor safety records, substandard quality and undesired productivity [16]. And digital technologies offer solutions. These include vast capabilities offered by the Internet of Things (IoT) [24,25]; unmanned aerial vehicles (UAVs) [26,27]; $3 \mathrm{D}$ printing [28,29]; augmented reality (AR) [30,31]; virtual reality (VR) [32-34]; mixed reality (MR) [35,36]; Building Information Modeling (BIM) [37-45]; Artificial Intelligence 
(AI); and intelligent decision support systems (DSS) [46-49]. At the organization level, digital engineering (DE) is proposed to complement the limitations of BIM beyond the boundaries of projects. So too, digital platforms for material procurement; robots; digital marketing; and digital tools for administration purposes, have profound positive impacts on the business front of companies [16,50].

There are many real-life examples and success stories of using various digital system in construction projects. Standing at the forefront of digitalization, there is compelling evidence for the advantages and benefits of using BIM in dealing with the complexities of multidisciplinary teams, identifying clashes, and reducing rework in and large-sized projects from around the globe, from Australia to Norway [51,52]. A coalescence of BIM and blockchain is proven effective in enhancing the effectiveness of managing financial transactions, enabling modern procurement methods, increase profit and cost savings [53]. In view of the full range of benefits, the construction sector has also embraced the use of UAVs in laying out sites; conducting remote and hazardous observations and surveying; risk-free site inspections; and safety monitoring $[23,26]$. Recently, the construction industry is observing a shift to the adoption of AI, with many benefits documented in the literature [20]. With AI, sophisticated algorithms are trained to learn from big data, and apply the acquired knowledge in revolutionizing industry practice, and improve productivity [54].

Although digitalization improves a wide range of construction business aspects that also ultimately produce better sustainable outcomes [50], digitalization adoption is fraught with challenges. Chief among these is that construction companies may need to consider changing almost every aspect of their business to achieve "digital transformation." Digital transformation is defined as "a process that aims to improve an entity by triggering significant changes to its properties through combinations of information, computing, communication, and connectivity technologies." [55] Digital transformation can be achieved in construction companies by focusing on five key activities, as illustrated in [50].

In the construction context, implementation of a digital technology relies heavily on various types of information: enough knowledge about the company such as the firm's structure, type of work, and the characteristics of human resources [56]. As illustrated in Figure 1, the digitalization of a construction firm is synonymous with successful digital transformation. This, in turn, requires the completion of five key activities, as described below:

- Integration of digital technologies into existing systems to exchange information among all construction market contributors.

- Improve business procedures with the aim of smoother exchange of data and information, control of products, and managing methods.

- Modification of organizational structures and human resources with the aim of choosing skillful workforces according to the digital transformation needs.

- Ensure that digital transformation is supported by all the staff and business contributors.

- Digital transformation investments must be assessed according to both financial and economic activities, not just economic ones.

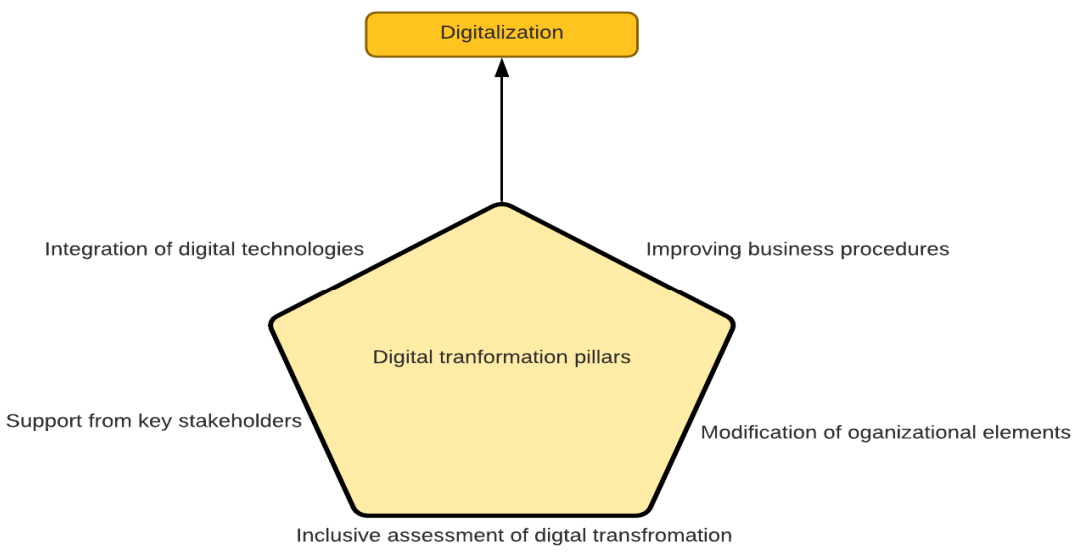

Figure 1. Digitalization and digital transformation activities. 
Achieving the aims and objectives of each of these pillars requires the development of a robust strategy, as discussed next.

\section{The Need for a Digital Transformation Strategy}

The digitalization of an existing firm is much more difficult than the establishment of a new digital company [22]. Hence, there is a need to develop a suitable strategy as a solution for construction companies to identify the main objectives, roadmaps, relevant actions, and methods of assessment [19]. This strategy transforms several essential elements and dimensions of business, including customer experience, business procedures, operations, stakeholders, and networks [57]. A company without a digital transformation strategy completes some isolated and small-sized projects, with little effect, where much-needed resources are wasted [19].

Several definitions for a digital transformation strategy exist in the literature $[58,59]$, yet no universal consensus has been reached to define it [60]. Simply, a digital transformation strategy is defined as the comprehensive vision of a firm in its move towards digitalization. To achieve this vision, a digital transformation strategy should include strategic measures; it should describe goals and tools for services, products, and value creation for a company/organization too [19]. Besides, adjustment of digital technologies' impacts and the nature of merging with internal firm's procedures and external firm's interfaces must be defined as essential elements of a digital transformation strategy.

Construction companies face many problems in developing a digital transformation strategy, mostly due to the novelty and complication of digitalization processes [61]. Familiarity with various dimensions of digital transformation and procedures of developing a successful digital transformation strategy are prerequisites, as discussed next.

\section{Challenges in Developing Such a Strategy}

The importance of digital transformation for companies, organizations, industries, and firms has resulted in the creation of a growing body of knowledge. However, recent studies suffer from a lack of a holistic approach to developing digital transformation strategies [62], where most existing studies represent a limited number of relevant factors and dimensions of digitalization. Bharadwaj, El Sawy, Pavlou, and Venkatraman [58], as will be discussed in great detail later on in the chapter, introduced four factors for providing a framework towards a digital transformation strategy for an organization: value creation, scope, scale, and speed of digital transformation. The speed of digital transformation is defined based on four factors: speed of product launching, speed of decision making, speed of supply chain orchestration, and speed of network formation and adaptation. Dimensions of a model for the development of a digital transformation strategy as provided by Matt, et al. [63] are the utilization of technology, structural changes, financial perspectives, and changes in value creation which can be defined as the effects of digital transformation on the companies' value chains due to the use of innovative technologies. These four items were believed to form a framework that informs companies in analyzing their existing capabilities, culminating in the development of a digital transformation strategy, as an ongoing procedure. Holotiuk and Beimborn [61] also developed a framework with eight dimensions: sales and customer experience; culture and leadership; abilities and human resources (HR) qualifications; forethought and vision; data and information technology (IT); functions; partners; and 40 critical success factors. Gimpel, et al. [64] proposed a framework of action fields following interviews with the chief digital officers from fifty organizations. This framework comprises six action fields: clients, value creation, functions, data, organization, and transformation management, in order to offer guidelines to engage in digital transformation.

Few studies have explored the development of a process for a digital transformation strategy. According to Schallmo, et al. [65], the integration of six steps results in the development of a digital transformation strategy. These are strategic principles, choices, forecasting, external and internal strategic analysis, and strategy formulization. Pflaum 
and Gölzer [66], also represent a four-stage process framework to facilitate the digital transformation of a firm, through the combination of top-down and bottom-up approaches. the steps are the business strategy step, knowledge creation, knowledge application, and the procedure of making decisions. However, they did not study the position of digital transformation strategy among the three levels of corporate, business, or functional strategies. As for finding the position of the digital transformation strategy, Lipsmeier, Kühn, Joppen, and Dumitrescu [19] argue that digital transformation strategy should be addressed at the corporate level. Hence, the digitalization of all business units should be aligned with the general strategic direction. The authors also conducted a process model for developing a digital transformation strategy as well as introducing the main factors of a digital transformation strategy. Albukhitan [67] also introduced a process for the development of a strategy by analyzing potential challenges that digital transformation attempts face, in the form of a process in six steps. Steps entailed identifying the vision, firms digital transformation capability, customers and workforce experience, and analyzing and choosing alternative solutions, creating action plans, providing the required infrastructure and skilled human resources.

The construction industry is innately complex; it is project-based, unique in terms of high demand and supply variability [68]. Moreover, squeezed profit margins due to different forms of delays and accidents bring other challenges [69], where construction practitioners suffer from improper communication and issues with accountability [70]. In light of these challenges, providing a strategy to direct and inform the digitalization journey is of utmost importance, however, there are few studies that offer a strategy for digitalization for the construction industry. Among these, Stoyanova [71] provides suggestions for enhancing the likelihood of success in the digital transformation of construction firms. Koscheyev, Rapgof, and Vinogradova [50] introduce various dimensions of digital transformation. Ernstsen, et al. [72] represent three visions of efficient construction, user-data-driven built environment, and value-driven computational design for the digital transformation of construction firms in the UK.

\section{Considerations in Formulating a Digital Transformation Strategy}

Several studies have attempted to define the key dimensions of digital transformation, as the elements which need to be defined early in the process $[58,63,73]$. These are discussed next.

The scope of a digital business strategy includes references to products, business actions, and the functions of running a company. The scope of a digital business strategy defines the relationships between digital elements and companies, industries, IT infrastructures, and the external environment. Furthermore, it can help to facilitate the assessing of various impacts of digital technology on firms' business strategy [58].

The scale of a digital business strategy is used as a profitability driver. There are four ways that the scale of a digital business strategy can benefit a company: fast scale up or down according to dynamic market conditions, change of scale based on big data, rapid scale due to network effects, and better scale through alliances and partnership-sharing assets with other companies [58].

The speed of a digital business strategy has an important role in digital business management, recognized as an important item that can benefit firms in terms of strategic management. Speed should be considered through the speed of product launching, speed of making decisions, speed of supply chain arrangement, speed of network formation, and adaptation [58].

The utilization of technology refers to the attitude of the company to the innovative technology, and the capability of a firm to benefit from it [63].

Changes in value creation often occur with the application of innovative technologies. The digital business strategy brings increased value through information, multisided business models, coordinated business models in a network, and control of digital industry architecture [58,63]. 
As for structural changes, the application of digital activities results in improving products and services; however, they often need advanced technological skills and expose companies to various risks due to lack of experience in a new domain. Hence, utilization of various technologies and different forms of value creation require substantial structural changes to provide a sound basis for new activities. Structural changes consist of changes in a company's organizational arrangement, especially efforts to diffuse innovative digital function into all corporate elements [63].

Financial perspectives are needed to achieve all other dimensions. Companies that suffer from financial pressures may face difficulties in finding external financial ways to support digital transformation. Hence, companies need to consider digital transformation strategies alongside their resources and funding capacities [63].

\section{Approaches to Defining a Digital Transformation Strategy}

Two major approaches are suggested for digital transformation, comprising of topdown and bottom-up. The former, also referred to as strategy-driven, includes changes to the business model by using modernizers. This is a long-term approach that focuses on changing the existing value chain, value proposition, and revenue modeling. The bottomup approach, or technology-driven approach, focuses on small or medium-sized changes in companies through using technology-driven tools and techniques. The objective of this approach is to drive slow improvements in productivity, employees' responsibility, and better customer experience and satisfaction [71]. The bottom-up approach is, however, inadequate for developing a successful digital transformation strategy, given the overarching impacts of digitalization on companies' fundamental components such as organizational structure, competencies, organizational procedures, and working culture. The bottom-up approach might have a detrimental impact on a company such as a productivity dip. The strategy-driven or top-down approach avoids such negative impacts and accelerates transformation. Nevertheless, developing a digital transformation strategy with a purely top-down approach is prone to some risks. These include increasing the likelihood of defining unrealistic objectives, scant attention to existing procedures, structures, initiatives, and a lack of buy-in from employees. The combination of these two approaches dominated by the bottom-up approach is suggested in the literature to tackle the problems facing digital transformation and speed up the process of digitalization $[19,66]$.

Another important factor is the position of a digital transformation strategy among three levels of corporate, business, and functional levels, as illustrated in Figure 2.

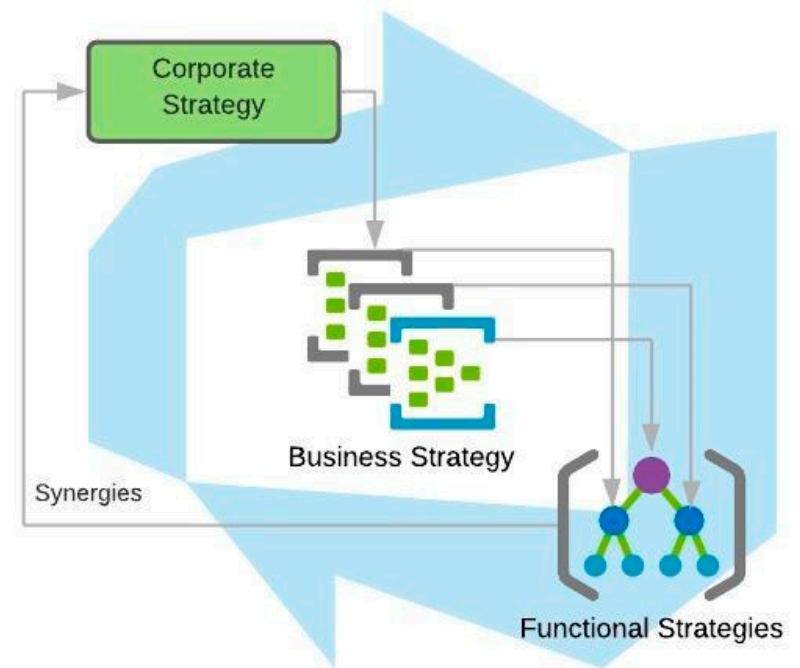

Figure 2. Strategy levels (adapter from Lipsmeier, Kühn, Joppen, and Dumitrescu [19]).

Corporate strategy corresponds to managing business units and the entire portfolio. The position of digital transformation strategy in relation to the corporate strategy can be 
considered in three different positions, including independent, being a part of it, or having the same weight as that of corporate strategy [65]. Most companies tend to develop their digital transformation strategy as a subsection of their corporate strategy [59]. With this, the strategy should be noted as an important consideration pertinent to the position of digital transformation. That is, digital transformation strategy should be defined at the corporate level and all other digitalization tools of business units should be aligned with the corporate strategy [19].

\section{The Process of Developing a Digital Transformation Strategy}

The development of a digital transformation strategy starts with defining a strategic direction according to digital guiding principles. This involves five components: digital vision, digital mission, digital policies, digital targets, and digital terms [19]. The first step is the definition of a strategic business vision for the proposed digital organization [66,67]. The strategic vision should consider long-term goals and short-term resources [67]. A digital vision can aim at the digital transformation of products and services or at value creation or both [19]. Vision should also involve business tools and digital use cases, based on business strategies and goals [66]. The vision for the digital transformation of construction firms has three dimensions, as follows [72]:

- Efficient construction focuses on expediting the construction procedure and enhancing efficiency. This can be achieved by concentrating on perspectives such as off-site construction, AI, BIM, lean construction, standardization, modularization, automation of design tasks, and alliancing business models.

- A user-data-driven built environment focuses on gathering real data, for instance, by IoT systems in the built environment. This vision requires the use of big data, IoT-based asset management, VR and 3D design, AR and maintenance, IoT-based energy utilization, sustainability, and health, and comfort of users.

- Value-driven computational design focuses on simulating various digital design alternatives and changing the design to satisfy various design criteria and clients' priorities within the construction procedure. This vision can be earned by concentrating on "digital fabrication on-site, gig economy, design simulations, blockchain, bespoke semi-automation, data-driven companies, distributed off-site production, and digital twin of the city."

The mission, pertinent to the digital transformation, however, seeks to find the reasons for the involvement of a company in digitalization; where digital policies propose regulations related to digital elements of a company such as digital management, digital initiative, data usage, information technology (IT), and safety, as well as the implementation of the digitalization process. Digital targets are initially described as qualitative values taken from digital vision, mission, and digital policies. In order to achieve the consistent realization of all these within a company, primary digital terms should be introduced [19].

After the identification of digital guiding principles, the next step is the assessment of the existing conditions of an organization in terms of digital transformation. To this end, systems, tools, and software applications should be assessed to evaluate their capabilities in fulfilling current and future requirements. The outcome of this step can facilitate decision-makers to understand which technologies, tools, and processes need to be improved [69]. Major tools for the assessment include market analysis and digital maturity assessment tools. Market analysis is of paramount importance. This tool provides the company with an up-to-date strategy [67]. A digital maturity tool should be provided to assess the framework of the IT infrastructure, organization, workforce, culture, partnering, technology, and functions, etc. in five levels of "unaware, conceptual, defined, integrated, and transformed" [66,67].

Subsequently, new systems and functions for facilitating employee jobs and clients' experiences should be provided. This can be achieved through proper use-cases of employees and new experiences for customers through digital technologies and platforms [67]. Use-cases should be prioritized and then implemented according to the allocated ranks [66]. 
A good tool for the structuring of required digital action plans-each functional area-is called "digital target" (Figure 3), which includes four factors. These are (1) digital vision which is a main objective of a functional area; (2) digital use-cases, which are digital tools for each working area; (3) strategic objectives, which should be determined in light of digitalization and aligns with digital guiding principles; (4) digital focus topics, extracted based on digital use cases, and work for communicating among functional areas and synchronizing primary actions in light of digitalization. Consequently, crossfunctional topics are obtained according to the digital focus topics for each functional area. Cross-functional topics are extracted by the combination of digital focus topics, leading to determining the principal digitalization topics for the business unit. The qualitative goals are defined as cross-functional topics and then can be changed into quantitative values [19].

Digital Vision

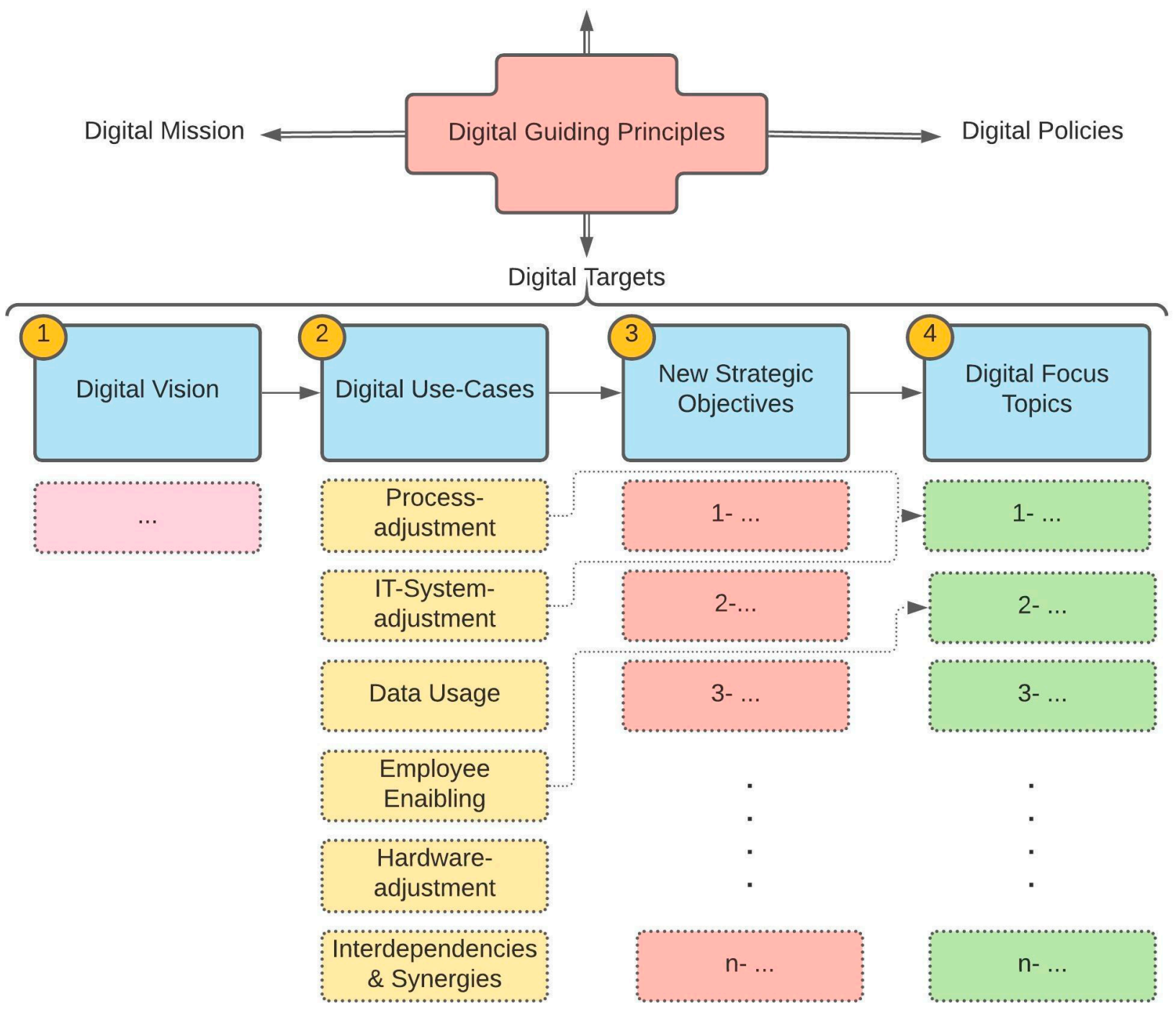

Figure 3. Digital target picture (adapted from Lipsmeier, Kühn, Joppen, and Dumitrescu [19]).

Knowledge creation is another step, which involves the modeling of all necessary data for possible problems related to use cases. The next step is knowledge application, in which, knowledge obtained from previous steps is analyzed by AI to forecast solutions for each use case [66]. Choosing the best solution that addresses digital objectives and people's experiences needs to be assessed according to their capabilities by a tool such as a comparison matrix of solutions [67]. 
The decision-making process is the last step, in which, the method of integration among knowledge-driven solutions and organizational decision processes is obtained (specification) [66]. Later, all of the digital objectives, solutions, and technologies are merged to form an action plan [67]. Vision, road map, and frameworks are also modified to be closer to the vision of a digital company [66].

It should be mentioned that firms need skilled staff members along the way towards digital transformation. These competent employees should work under the supervision of someone who possesses transformation leadership skills [63]. Therefore, preparation of the skillful human resources, with expertise in digital change management, is an important step for digital transformation [67].

\section{Conclusions}

Construction represents a significant proportion of the economy in both developing and developed nations. Yet, the profitability of construction firms, generally, remains below par when compared with other sectors within an economy. Moreover, construction activity is a major source of energy consumption, greenhouse gas emissions, and waste generation. Competitiveness and sustainability, therefore, are two key challenges the construction industry must face worldwide. Fortunately, there is a way forward and that is through the digitalization of the industry at the firm level. The other good news is that the efficiency gains to be had through the digitalization of construction firms can be expected to repair the poor sustainability record of the industry, as it currently operates. Specifically, cost reductions, efficiency gains, and better returns on assets that digitalization promises would be achieved through reduced energy consumption, better resource and material utilizations, and stronger control of waste, pollution, and carbon emissions.

However, meaningful digital transformation cannot be successfully realized without a strong commitment to such change. This means more is required than the frequently observed manner in which firms attempt to transition to a digitized business model; that is, employing IT experts to run introduced digitalization software on new hardware platforms, while also persisting with traditional forms of operations. Running parallel construction management practices within a firm —older analog systems and new digitized systemshas not been shown to be an effective means of evolving firms to full digitalization. What is needed is genuine change management. For that to be realized, a clear digitalization transition strategy must be formulated and implemented.

This study has documented the way forward in this regard. The need for change is argued. The quest for digitalization is shown to require firm-level digital transformation. The dimensions of a digital strategy are presented. Finally, the various approaches to embracing a digital transformation strategy are discussed. It is hoped that this paper will provide practitioners intent on making the transition to digitalization with a guiding framework for making the changes.

Author Contributions: Conceptualization, B.N. and M.R.H.; methodology, M.R.H. and I.M.; analysis of the literature, B.N.; writing—original draft preparation, B.N. and I.M.; writing—review and editing, M.R.H., J.A., and E.K.Z.; visualization, J.A.; supervision and quality control, E.K.Z. All authors have read and agreed to the published version of the manuscript.

Funding: This research received no external funding.

Institutional Review Board Statement: Not applicable.

Informed Consent Statement: Not applicable.

Data Availability Statement: Not applicable.

Conflicts of Interest: The authors declare no conflict of interest. 


\section{References}

1. Barbosa, F.; Woetzel, J.; Mischke, J.; Ribeirinho, M.J.; Sridhar, M.; Parsons, M.; Bertram, N.; Brown, S. Reinventing Construction Through a Productivity Revolution. Available online: https:/ /www.mckinsey.com/industries/capital-projects-andinfrastructure/ our-insights/reinventing-construction-through-a-productivity-revolution (accessed on 12 September 2020).

2. Sategna, L.G.; Meinero, D.; Volontà, M. Digitalising the Construction Sector; Committee for European Construction Equipment: Brussels, Belgium, 2019.

3. Leviäkangas, P.; MokPaik, S.; Moon, S. Keeping up with the pace of digitization: The case of the Australian construction industry. Technol. Soc. 2017, 50, 33-43. [CrossRef]

4. Ghodoosi, F.; Bagchi, A.; Hosseini, M.R.; Vilutienè, T.; Zeynalian, M. Enhancement of bid decision-making in construction projects: A reliability analysis approach. J. Civ. Eng. Manag. 2021, 27, 149-161. [CrossRef]

5. Loosemore, M. Australia's Construction Industry Must Unite around a Cohesive Strategy. Available online: https: //www.thefifthestate.com.au/innovation/building-construction/australias-construction-industry-must-unite-around-acohesive-strategy / (accessed on 30 October 2020).

6. Fathalizadeh, A.; Hosseini, M.R.; Vaezzadeh, S.S.; Edwards, D.J.; Martek, I.; Shooshtarian, S. Barriers to sustainable construction project management: The case of Iran. Smart Sustain. Built Environ. 2021. [CrossRef]

7. Hosseini, M.R.; Banihashemi, S.; Martek, I.; Golizadeh, H.; Ghodoosi, F. Sustainable Delivery of Mega projects in Iran: Integrated Model of Contextual Factors. J. Manag. Eng. 2018, 34, 05017011. [CrossRef]

8. Gruszka, A.; Jupp, J.R.; DeValence, G. Digital Foundations: How Technology Is Transforming Australia's Construction Sector. Available online: https:/ / opus.lib.uts.edu.au/handle/10453/124861 (accessed on 30 October 2020).

9. Hampson, K.D.; Brandon, P. Construction 2020-A Vision for Australia's Property and Construction Industry; CRC Construction Innovation: Queensland University of Technology: Brisbane City, QLD, Australia, 2004.

10. The Productivity Commission Growing the Digital Economy in Australia and New Zealand: Maximising Opportunities for Small Medium Enterprises (SMEs). Available online: https:/ / www.pc.gov.au/research/completed/growing-digital-economy (accessed on 30 October 2020).

11. Hilty, L.M.; Aebischer, B. Ict for sustainability: An emerging research field. In ICT Innovations for Sustainability; Springer: Berlin/Heidelberg, Germany, 2015; pp. 3-36.

12. Grubic, T.; Jennions, I. Remote monitoring technology and servitised strategies-factors characterizing the organizational application. Int. J. Prod. Res. 2018, 56, 2133-2149. [CrossRef]

13. Kaklauskas, A.; Zavadskas, E.K.; Binkyte-Veliene, A.; Kuzminske, A.; Cerkauskas, J.; Cerkauskiene, A.; Valaitiene, R. Multiple Criteria Evaluation of the EU Country Sustainable Construction Industry Lifecycles. Appl. Sci. 2020, 10, 3733. [CrossRef]

14. Nosratabadi, S.; Mosavi, A.; Shamshirband, S.; Zavadskas, E.K.; Rakotonirainy, A.; Chau, K.W. Sustainable business models: Areview. Sustainability 2019, 11, 1663. [CrossRef]

15. Stanujkic, D.; Popovic, G.; Zavadskas, E.K.; Karabasevic, D.; Binkyte-Veliene, A. Assessment of Progress towards Achieving Sustainable Development Goals of the "Agenda 2030" by Using the CoCoSo and the Shannon Entropy Methods: The Case of the EU Countries. Sustainability 2020, 12, 5717. [CrossRef]

16. Hosseini, M.R.; Martek, I.; Banihashemi, S.; Chan, A.P.; Darko, A.; Tahmasebi, M. Distinguishing characteristics of corruptionrisks in Iranian construction projects: A weighted correlation network analysis. Sci. Eng. Ethics 2020, 26, 205-231. [CrossRef] [PubMed]

17. Gartner Gartner Glossary: Digitalization. Available online: https://www.gartner.com/en/information-technology/glossary/ digitalization (accessed on 5 January 2020).

18. Plekhanov, D.; Netland, T. Digitalisation stages in firms: Towards a framework. In Proceedings of the 26th EurOMA Conference, Helsinki, Finland, 17-19 June 2019.

19. Lipsmeier, A.; Kühn, A.; Joppen, R.; Dumitrescu, R. Process for the development of a digital strategy. Procedia CIRP 2020, 88, 173-178. [CrossRef]

20. Jafari, K.G.; Noorzai, E.; Hosseini, M.R. Assessing the capabilities of computing features in addressing the most common issues in the AEC industry. Constr. Innov. 2021. [CrossRef]

21. Ghansah, F.A.; Owusu-Manu, D.-G.; Ayarkwa, J.; Edwards, D.J.; Hosseini, M.R. Exploration of latent barriers inhibiting project management processes in adopting smart building technologies (SBTs) in the developing countries. Constr. Innov. 2021. [CrossRef]

22. Ianenko, M.; Ianenko, M.; Kirillova, T.; Amakhina, S.; Nikitina, N. Digital transformation strategies of trade enterprises: Key areas, development and implementation algorithms. In IOP Conference Series: Materials Science and Engineering; IOP Publishing: London, UK, 2020; Volume 940, p. 012051.

23. Elghaish, F.; Matarneh, S.; Talebi, S.; Kagioglou, M.; Hosseini, M.R.; Abrishami, S. Toward digitalization in the construction industry with immersive and drones technologies: A critical literature review. Smart Sustain. Built Environ. 2020. [CrossRef]

24. Ghosh, A.; Hosseini, M.R.; Al-Ameri, R.; Kaklauskas, G.; Nikmehr, B. Internet of Things (IoT) for digital concrete quality control (DCQC): A conceptual framework. In Proceedings of the 13th International Conference Modern Building Materials, Structures and Techniques; VGTU Press: Vilnius, Lithuania, 2019.

25. Ghosh, A.; Edwards, D.J.; Hosseini, M.R. Patterns and trends in Internet of Things (IoT) research: Future applications in the construction industry. Eng. Constr. Archit. Manag. 2020, 28, 457-481. [CrossRef]

26. Golizadeh, H.; Hosseini, M.R.; Martek, I.; Edwards, D.; Gheisari, M.; Banihashemi, S.; Zhang, J. Scientometric analysis of research on "remotely piloted aircraft". Eng. Constr. Archit. Manag. 2019, 27, 634-657. [CrossRef] 
27. York, D.D.; Al-Bayati, A.J.; Al-Shabbani, Z.Y. Potential Applications of UAV within the Construction Industry and the Challenges Limiting Implementation. In Construction Research Congress 2020: Project Management and Controls, Materials, and Contracts, 2020; American Society of Civil Engineers: Reston, VA, USA, 2020; pp. 31-39.

28. Romdhane, L.; El-Sayegh, S.M. 3D Printingin Construction: Benefits and Challenges. Int. J. Struct. Civ. Eng. Res. 2020, 9, 314-317. [CrossRef]

29. El-Sayegh, S.; Romdhane, L.; Manjikian, S. A critical review of 3D printing in construction: Benefits, challenges, and risks. Arch. Civ. Mech. Eng. 2020, 20, 34. [CrossRef]

30. Noghabaei, M.; Heydarian, A.; Balali, V.; Han, K. Trend Analysis on Adoption of Virtual and Augmented Reality in the Architecture, Engineering, and Construction Industry. Data 2020, 5, 26. [CrossRef]

31. Fenais, A.S.; Ariaratnam, S.T.; Ayer, S.; Smilovsky, N. A review of augmented reality applied to underground construction. J. Inf. Technol. Constr. 2020, 25, 308-324. [CrossRef]

32. Zhang, Y.; Liu, H.; Kang, S.-C.; Al-Hussein, M. Virtual reality applications for the built environment: Research trends and opportunities. Autom. Constr. 2020, 118, 103311. [CrossRef]

33. Lucas, J. Rapid development of Virtual Reality based construction sequence simulations: A case study. ITcon 2020, 25, 72-86. [CrossRef]

34. Ahmed, S. A review on using opportunities of augmented reality and virtual reality in construction project management. Organ. Technol. Manag. Constr. Int. J. 2018, 10, 1839-1852. [CrossRef]

35. Cheng, J.C.; Chen, K.; Chen, W. State-of-the-art review on mixed reality applications in the AECO industry. J. Constr. Eng. Manag. 2020, 146, 03119009. [CrossRef]

36. Rokhsaritalemi, S.; Sadeghi-Niaraki, A.; Choi, S.-M. A Review on Mixed Reality: Current Trends, Challenges and Prospects. Appl. Sci. 2020, 10, 636. [CrossRef]

37. Elghaish, F.; Abrishami, S.; Hosseini, M.R.; Abu-Samra, S. Revolutionising cost structure for integrated project delivery: A BIM-based solution. Eng. Constr. Archit. Manag. 2020. [CrossRef]

38. Hamidavi, T.; Abrishami, S.; Hosseini, M.R. Towards intelligent structural design of buildings: A BIM-based solution. J. Build. Eng. 2020, 32, 101685. [CrossRef]

39. Khalesi, H.; Balali, A.; Valipour, A.; Antucheviciene, J.; Migilinskas, D.; Zigmund, V. Application of Hybrid SWARA-BIM in Reducing Reworks of Building Construction Projects from the Perspective of Time. Sustainability 2020, 12, 8927. [CrossRef]

40. Pavlovskis, M.; Migilinskas, D.; Antucheviciene, J.; Kutut, V. Ranking of heritage building conversion alternatives by applying BIM and MCDM: A case of Sapieha Palace in Vilnius. Symmetry 2019, 11, 973. [CrossRef]

41. Qin, X.; Shi, Y.; Lyu, K.; Mo, Y. Usinga TAM-TOE model to explore factors of Building Information Modelling (BIM) adoption in the construction industry. J. Civ. Eng. Manag. 2020, 26, 259-277. [CrossRef]

42. Wang, G.; Wang, P.; Cao, D.; Luo, X. Predicting behavioural resistance to BIM implementation in construction projects: Ane mpirical study integrating technology acceptance model and equity theory. J. Civ. Eng. Manag. 2020, 26, 651-665. [CrossRef]

43. Zhang, L.; Yuan, J.; Xia, N.; Ning, Y.; Ma, J.; Skibniewski, M.J. Measuring value-added-oriented BIM climate in construction projects: Dimensions and indicators. J. Civ. Eng. Manag. 2020, 26, 800-818. [CrossRef]

44. Vilutiene, T.; Kalibatiene, D.; Hosseini, M.R.; Pellicer, E.; Zavadskas, E.K. Building information modeling (BIM) for structural engineering: A bibliometric analysis of the literature. Adv. Civ. Eng. 2019, 2019, 5290690. [CrossRef]

45. Vilutiene, T.; Hosseini, M.R.; Pellicer, E.; Zavadskas, E.K. Advanced BIM applications in the construction industry. Adv. Civ. Eng. 2019, 2019, 6356107. [CrossRef]

46. Kaklauskas, A.; Abraham, A.; Dzemyda, G.; Raslanas, S.; Seniut, M.; Ubarte, I.; Kurasova, O.; Binkyte-Veliene, A.; Cerkauskas, J. Emotional, affective and biometrical states analytics of a built environment. Eng. Appl. Artif. Intell. 2020, 91, 103621. [CrossRef]

47. Stojčić, M.; Zavadskas, E.K.; Pamučar, D.; Stević, Ž.; Mardani, A. Application of MCDM methods in sustainability engineering: A literature review 2008-2018. Symmetry 2019, 11, 350. [CrossRef]

48. Zavadskas, E.K.; Antucheviciene, J.; Kar, S. Multi-objective and multi-attribute optimization for sustainable development decision aiding. Sustainability. 2019, 11, 3069. [CrossRef]

49. Fallahpour, A.; Wong, K.Y.; Rajoo, S.; Olugu, E.U.; Nilashi, M.; Turskis, Z. A fuzzy decision support system for sustainable construction project selection: An integrated FPP-FIS model. J. Civ. Eng. Manag. 2020, 26, 247-258. [CrossRef]

50. Koscheyev, V.; Rapgof, V.; Vinogradova, V. Digital transformation of construction organizations. In IOP Conference Series: Materials Science and Engineering; IOP Publishing: Saint-Petersburg, Russian, 2019; Volume 97, p. 012010.

51. Mignone, G.; Hosseini, M.R.; Chileshe, N.; Arashpour, M. Enhancing collaboration in BIM-based construction networks through organisational discontinuity theory: A case study of the new Royal Adelaide Hospital. Archit. Eng. Des. Manag. 2016, 12, 333-352. [CrossRef]

52. Merschbrock, C.; Hosseini, M.R.; Martek, I.; Arashpour, M.; Mignone, G. Collaborative role of sociotechnical components in BIM-based construction networks in two hospitals. J. Manag. Eng. 2018, 34, 05018006. [CrossRef]

53. Elghaish, F.; Abrishami, S.; Hosseini, M.R. Integrated project delivery with blockchain: An automated financial system. Autom. Constr. 2020, 114, 103182. [CrossRef]

54. Darko, A.; Chan, A.P.C.; Adabre, M.A.; Edwards, D.J.; Hosseini, M.R.; Ameyaw, E.E. Artificial intelligence in the AEC industry: Scientometric analysis and visualization of research activities. Autom. Constr. 2020, 112, 103081. [CrossRef]

55. Vial, G. Understanding digital transformation: A review and a research agenda. J. Strateg. Inf. Syst. 2019, 28, 118-144. [CrossRef] 
56. Sackey, E.; Tuuli, M.; Dainty, A. Sociotechnical systems approach to BIM implementation in a multi-disciplinary construction context. J. Manag. Eng. 2015, 31, A4014005. [CrossRef]

57. Ismail, M.H.; Khater, M.; Zaki, M. Digital business transformation and strategy: What do we know so far. Camb. Serv. Alliance 2017, 10. [CrossRef]

58. Bharadwaj, A.; ElSawy, O.A.; Pavlou, P.A.; Venkatraman, N. Digital business strategy: Toward a next generation of insights. MIS Q. 2013, 37, 471-482. [CrossRef]

59. Schallmo, D.; Williams, C.A.; Lohse, J. Clarifying Digital Strategy-Detailed Literature Review of Existing Approaches. In ISPIM Conference Proceedings, 2018; The International Society for Professional Innovation Management (ISPIM): Stockholm, Sweden, 2018; pp. 1-21.

60. Dang, D.; Vartiainen, T. Digital strategy patterns in information systems research. In Proceedings of the PACIS 2019 Proceedings, Xi'an, China, 8-12 July 2019.

61. Holotiuk, F; Beimborn, D. Critical success factors of digital business strategy. In Proceedings of the Track 9-Business Innovations and Business Models, St. Gallen, Switzerland, 12-15 February 2017.

62. Korachi, Z.; Bounabat, B. General Approach for Formulating a Digital Transformation Strategy. J. Comput. Sci. 2020, 16, 493-507.

63. Matt, C.; Hess, T.; Benlian, A. Digital transformation strategies. Bus. Inf. Syst. Eng. 2015, 57, 339-343. [CrossRef]

64. Gimpel, H.; Hosseini, S.; Huber, R.X.R.; Probst, L.; Röglinger, M.; Faisst, U. Structuring Digital Transformation: A Framework of Action Fields and its Application at ZEISS. J. Inf. Technol. Theory Appl. 2018, 19, 31-54.

65. Schallmo, D.; Williams, C.A.; Lohse, J. Digital Strategy-Integrated Approach and Generic Options. Int. J. Innov. Manag. 2019, 23, 1940005. [CrossRef]

66. Pflaum, A.A.; Gölzer, P. The IoT and digital transformation: Toward the data-driven enterprise. IEEE Pervasive Comput. 2018, 17, 87-91. [CrossRef]

67. Albukhitan, S. Developing Digital Transformation Strategy for Manufacturing. Procedia Comput. Sci. 2020, 170, 664-671. [CrossRef]

68. Morris, P.W. Project management in the construction industry. Wiley Guide Manag. Proj. 2004, 1350-1367.

69. Behera, P.; Mohanty, R.P.; Prakash, A. An investigation of implementation issues, process phases and knowledge areas of project management in the performance of construction supply chains. Int. J. Proj. Organ. Manag. 2018, 10, 137-157. [CrossRef]

70. Patanakul, P.; Kwak, Y.H.; Zwikael, O.; Liu, M. What impacts the performance of large-scale government projects? Int. J. Proj. Manag. 2016, 34, 452-466. [CrossRef]

71. Stoyanova, M. Good Practices and Recommendations for Success in Construction Digitalization. TEM J. $2020,9,42-47$.

72. Ernstsen, S.N.; Whyte, J.; Thuesen, C.; Maier, A. How Innovation Champions Frame the Future: Three Visions for Digital Transformation of Construction. J. Constr. Eng. Manag. 2020, 147, 05020022. [CrossRef]

73. Mitroulis, D.; Kitsios, F. Digital Transformation Strategy: A literature review. In Proceedings of the 6th National Student Conference of HELORS, Xanthi, Greece, 28 February-2 March 2019; pp. 59-61. 